formulæ; the fundamental equations remain everywhere the same. In other words, the question is one of the theory of all conditions whereby heterogeneous substances or heterogeneous phases of the same substance have assumed, after reciprocal influence, a condition of equilibrium independent of the time.

The general theory of these conditions has been developed by J. Willard Gibbs sixteen years ago; a German edition of this magnificent and incredibly many-sided investigation is at present in the press. Through van 't Hoff and Arrhenius we are placed in a position to insert in the equations of this man of science, which contain necessarily a great number of yet unknown functions, the expressions for these functions, together with the numerical constants, and to thus solve the problem numerically from case to case.

It must, however, be borne in mind that the functions in question, expressing as the sum of its single forms the total energy of the system considered, are yet known only for the cases of gases and dilute solutions, i.e. for the cases where the inner energy has become independent of the volume. As far as the knowledge of the equation of condition reaches, extends the possibility of mastering the heterogeneous conditions and chemical equilibria. And we see at this place how the different parts of general chemistry reach to one another the hand; the solution of the problems which were mentioned in the first part of this address is also, for that just discussed, the unavoidable condition of progress.

But with the range just measured off, great as it is, the limits of the province of the van 't Hoff-Arrhenius theory are not yet reached. The dissociation discovered by Arrhenius is an electrolytic one. Accordingly, the immense number of phenomena, in which the electrically charged ions participate, belong likewise with those which here receive a new light. The question as to the source and maintenance of the electrical energy in the galvanic elements, as to the conduction of current in electrolytes, as to the meaning of galvanic polarization, are only single points in this field. Electro-chemistry in the widest sense, and, indeed, as much so that part which is concerned with essentially electrical questions as that which studies chemical questions, has already received most valuable furtherance from our theory, and has yet more in prospect.

It is natural, as against this exposition, to propose the question how the theory of van ' $t$ Hoff and Arrhenius has responded to the requirements which have been made upon it in a so extraordinarily wide-reaching and varied manner. Since I belong to the few who make use of this aid in their investigations, I must freely confess that my judgment in this matter may be looked upon as subjective ; but since, on the other hand, I hold to both theories unfortunately, not the position of a father, but only that of an uncle of rather distant relationship, you may trust me that at the time of first meeting them I was rather inclined to repel than to greet them. I can then only personally declare that no scientific idea produced in my time has assisted me in such measure as bas this one, and that I have further gained the impression that the great scientific fields named have received likewise unusual furtherance from this idea. In particular the extraordinarily manifold and severe test which lies in the numberless numerical eonsequences of the theory in all possible fields, has yielded such a number of confirmations that the relatively rare cases where the unprejudiced decision was "insufficient" entirely vanish. Naturally must not be considered the judgment of those who, with insufficient qualifications, set themselves up as judges, who do not attempt to test the theory, but only to refute it. The misunderstanding and false conceptions from which such "refutations" proceeded have been in fact of such kind that thereout no real progress, which is the end of every scientific undertaking, has resulted.

I hasten to close. The concise review of the working ground of general chemistry, which I have just attempted to give, shows to what great extent chemistry has made use of physical means to solve her problems. It is, therefore, not especially necessary to urge my chemical associates that they should follow up the study of physics and acquire the necessary mathematical knowledge. It is cared for at many Universities by the more far-seeing teachers of chemistry, that this indispensable knowledge is made as accessible as possible to our youths, and my personal experience has shown me that such opportunities are gladly and profitably used.

But the reverse does not present so favourable an aspect. The science of physics requires for its extension and development exhaustive chemical knowledge in many directions. All

NO. I I 73 , VOL. 45 j phenomena in which the special character of matter comes into question require for their study an extended knowledge of just this character, i.c. chemical knowledge. And I cannot avoid complaining that in this direction too little is done. In the more recent physical literature, I have met not seldom chemical views, which were, in short, fearful, and which gave to the interpretation of the observed phenomena an entirely false direction. The physicist is only too inclined to consider chemistry as an inferior science, of which he knows a yreat suffi. ciency if, in the early part of his student life, he has once heard its lectures. Nothing can be more wrong than such a view. By reason of its richer and more special store of facts, chemistry really remains behind physics in its development into a rational science, and it will ever so remain, in the same way as physics remains behind astronomy or mathematics. But directly for this reason the beginning of the student years is the only time in which to become acquainted with the varied details of chemical phenomena, and to take up the enormous range of experience here offered. For, according to experience, the physicist never learns them later. The history of our science points out a number of men, who, from chemists, have become physicists of high rank; I need name only Regnault, Faraday, Davy, Magnus, Hittorf. But I cannot name a single man of science who, after having been trained as a physicist, has made one purely chemical discovery of importance, for it never occurs that a physicist later learns chemistry. The great range of empirical experience can only be incorporated into the memory at a time when the latter is fresh, and it is usually already too late but a few semesters after the siudent life has been begun.

I can, therefore, not urge my physical colleagues enough : send your students at first for a few semesters into the chemical laboratory. We chemists must indeed do our part, in suitably rearranging the laboratory instruction; the practice in qualitative analysis should, in particular, be greatly cut down, and in its place preparative work in its widest sense, together with the typical forms of quantitative analysis, should be taken up. But since the same requirements are to be made upon the education of the future teacher of the natural sciences and mathematics in the Gymnasia and Realschulen, it will not be difficult to soon find the methods best adapted for the chemical education of all non-chemists, without injuring the immediate purpose of the chemical laboratories-the training of chemical specialists.

\section{THE GENERAL CIRCULATION OF THE} $A T M O S P H E R E .^{1}$

IF the question of the general circulation of the atmosphere were referred to a meeting of educated people, one might be sure that ninety out of a hundred who could give any answer at all would explain it by the time-honoured equatorial and polar current ; if anyone initiated in the subject sat near, one would observe a pitying smile upon his lips, and, if asked for his opinion, he would relegate that current, of sacred memory, to the region of the fables, or at most only allow it to hold sway, with certain limitations, in the tropical and sub-tropical zones, the region of the trade-winds; the temperate and cold zones however would be reserved for the dominion of the variable winds, and of newly arisen cyclones and anticyclones, of which we cannot tell whence they come and whither they go, i.e. for the origin and disappearance of which we cannot lay down any laws. And if there were several of these initiated persons present, a discussion would at once occur, from which no one could obtain a clear idea, and which would leave everyone with the impression that nothing certain was known about the subject. I suppose that you have been present at such a discussion, and have appealed to me to explain to you the present state of our knowledge of this subject.

I undertake this task the more willingly, since the question of the general circulation of the atmosphere has but recently entered upon a new stage, which marks a great step towards the complete solution of the question, and becanse it is very desirable to obtain as wide a diffusion as possible for this theory which corresponds to the present state of the science.

In this question especially, as in many others, the history of the development is exceedingly instructive, and of the greatest value in aiding a comprehension of the subject. I propose, therefore, that you should follow me through the different stages

$r$ Translation of a lecture delivered by Dr. J. M. Pernter before the Scientific Club in Vienna. 
which the explanation of the general circulation of the atmosphere has undergone; little or nothing more will then be wanting in order to understand the answer to the question at issue.

Dove was the first person who advanced a theory of the general circulation of the atmosphere after meteorology took a place among the exact sciences. He considered the question from a high and correct stand-point, because he considered the atmospheric envelope of the earth as a whole, which received its motion from the sun, the universal motor. According to his theory, the explanation of the general circulation of the atmosplere took the following form :-

The heat of the sun is not uniformly distributed over the earth's surface, but decreases from the equator to the poles. The greatest heat occurs at the equator, and the least at the poles. The air which is greatly heated at the equator must consequently rise, an ascending current must be developed there (the celebrated courant ascendant). The zone of calms is the region of the ascending air current. The air carried upwards must flow away above towards the poles, while, owing to the rotation of the earth, it endeavours to deviate to the right; the equatorial current is originated as an upper south-west wind, in the higher strata of the atmosphere. The flow of the upper air towards the poles is compensated below by the flow of the air towards the equator, and this polar current seems to be turned away towards the west owing to the rotation of the earth; it appears on the earth's surface as a north-west wind, and blows as far as the zone of calms, where it ceases, and the air brought with it is carried upwards in the ascending air current, where the circulation then begins afresh.

You see that this theory leads to a circulation of the air between pole and equator. The air rises at the equator and flows towards the poles, in order to descend there and to flow again towards the equator. But Dove states expressly that the equatorial current partially descends, even in the temperate latitudes, down to the bed of the polar current. If this happens, and according to Dove this continually occurs, then both winds, the equatorial and polar currents, begin the conflict for the mastery. The variable winds of the temperate zone arise out of this conflict, and Dove deduced therefrom his law of wind gyration. The description which he gave of this conflict of the opposing equatorial and polar currents is a thoroughly masterly picture, and it is in a great measure owing to this elaborate completion of his exposition that his theory of the general circulation of the atmosphere and his law of wind gyration were accepted by scientific men. The reader is carried away by it as if he were present at the conflict of the winds in AEolus's mythological cave, and he is inclined to believe that science verifies the ancient mythology so far as regards the lower latitudes. Dove's theory found an actual support in the trade-winds, and in the law of wind gyration which generally obtains in Central Europe. In fact, in our regions, the wind rotates very frequently from east through south to west and north. Dove's explanation of this, the conflict of the equatorial and polar currents must have appeared to be correct as long as no more serious investigations existed.

Since 1863 ; weather telegraphy and synoptic weather charts have led to the discovery of the baric wind law (Buys Ballot's law), and the position was at once changed. We learned that the winds depend upon the differences of pressure which prevail over the region under consideration, and that they circulate round the place of lowest pressure ; i.e., with us, they fow to the place of lowest pressure, in spirals opposite to the movement of watch hands.

It was now said that the cause of the winds in our latitudes was not the great heating of the air at the equator, but the differences of pressure which were formed in the temperate zone. The law of wind gyration also became untenable. It was found that the swirls which arose about the place of lowest pressure do not stand still, but move, and it was seen that Dove's law of wind gyration for places which lie northwards of the tracks of these swirls does not hold good, in fact that the rotation is exactly the reverse.

The reason why Dove's law of wind gyration mostly holds good in Germany and Central Europe, was found to be that the tracks of the swirls almost always lie to the northwards of Central Europe, and therefore the law must hold good there. But as often as a swirl moves more southwards all places in Central Europe which lie to the north of it have a wind rotation which is opposed to Dove's law.
The equatorial and polar currents, so far as regards the higher latitudes, were thus driven off the field, and the conflict between them, so beautifully described, was again relegated to the mythical cave of Eolus. As it was feared that the wheat might be thrown away with the chaff, it was wished that the equatorial and polar current should be banished from the higher latitudes altogether, but left, in a more limited sense, only in the regions of the trade-winds-ivetween the zone of calms and about $30^{\circ}$ north and south latitude ; for here it was clear that Dove's theory held good. People unceremoniously denied the right of the polar current to blow beyond the 35th parallel, for in this latitude, as observations show, a band of high pressure encircles the whole earth, while from there the pressure decreases both towards the equator and the poles. But according to the baric wind law the wind can only flow from a place of higher to one of lower pressure; the air can therefore only flow from the $35^{\text {th }}$ parallel towards the pole, and not the reverse. The polar current was thereby banished without mercy from the higher latitudes. The equatorial current fared somewhat better in the upper regions. Many persons allowed it to remain in a small degree, especially those who recognized the accuracy of the calculation according to which in the higher atmosphere, about $4000 \mathrm{~m}$. and over, the pressure decreases from the equator to the pole. But very few persons knew what to make of this equatorial current in the upper regions, and so at all events it was little regarded. Generally speaking, the réoime of cyclones and anticyclones was established for the higher latitudes, and people were completely absorbed in investigating the details of their qualities and tracks, without having hitherto succeeded in obtaining a satisfactory cxplanation of their origin and development. With regard to the propagation of cyclones, it was observed that with few exceptions they advanced from the westward to the eastward. Gradually, opinions became general that it was the south-west and west wind of the upper regions which brought the cyclones with it; some persons explained this west wind in the upper regions as the equatorial current. But, on the whole, the general opinion of this period favoured the rejection of Dove's polar and equatorial current, and the explanation of all winds by the prevalent differences of pressure, without being able to account for the origin of the latter.

Dove was of an excitable temperament, and he strongly combated these new views, and laid too much weight on the defence of the defective portion of his theory. His contest was fruitless, and only caused him to be accused with some justice of hindering the progress of meteorology by his great authority. Dove at length remained silent, and the funeral anthem of the polar and equatorial current was then chanted.

Muihry, a well-known meteorologist of the Dove school, survived him, and constantly raised his voice in favour of Dove's equatorial and polar current; he attentively followed the progress of meteorology until his death, a few years ago, and the way in which he frequently warned meteorologists against entirely excluding the equatorial and polar current from their considerations is quite stirring. He was continually trying to turn attention to it, but with him disappeared the last defender of Dove's theory.

But while meteorologists were almost exclusively concerned with the details of the phenomena offered by cyclones and anticyclones, and almost lost sight of the great problems which the consideration of the general circulation of the atmosphere afford: a revolution was being prepared, at first only individually, but gradually more generally, which disposed minds to the more favourable consideration of the general movements of the atmosphere.

More than thirty years ago, Ferrel, the great American meteorologist, was occupied with the question of the general circulation of the atmosphere. He developed its laws in a mathematical form, and arrived at the following theory :-

Three great zones of calms exist round the earth, one at the equator (or near it), usually called the calm-belt, the second and third $35^{\circ}$ north and south of the equator, the so-called "horselatitudes." Between the calm-belt and the horse-latitudes, the north-east or south-east trade-wind prevails at the surface of the earth, and in the higher regions above them the anti-trade (south-west or north-west). In the calm-belt, in which no other than an ascending movement of the air exists up to the greatest heights, an upheaval of the air occurs, and in latitude $35^{\circ}$ a descent of the same. Northwards of $35^{\circ} \mathrm{N}$., and southward of $35^{\circ} \mathrm{S}$., south-west and west winds prevail both at ihe earth's surface and at great altitudes, while at a mean height a return

$$
\text { NO. I } 173 \text {, VOL. 45] }
$$


north-westerly current prevails. The heat of the sun, or difference of temperature between equator and pole, is the cause of this general circulation of the atmosphere, as Dove maintained; the deviation of the wind from the direction of the meridians arises from the rotation of the earth.

This whole theory of the circulation of the atmosphere, which Ferrel deduced by mathematical means, differs considerably from Dove's, but shows that Dove's fundamental idea was sound and worthy of respect.

Ferrel's investigation certainly remained long unknown in Europe, and when at length it became known, it was only received with a purely theoretical interest. It seemed to have no connection with the present almost exclusively interesting question of the origin, development, and propagation of cyclones, and so it was in fact set aside; although from that time people frequently referred to it, and began to pay more attention to the currents of the general circulation. But it was only in 1885 that Sprung in his treatise on meteorology could write: "And so the conviction is now often expressed that we have gone too far in accrediting the individual systems (cyclones and anticyclones.) with the sole control over the motions of the air in higher latitudes "; and he then sets up a system of general circulation based on the same principles as those of Ferrel. Sprung's system corresponds tolerably well to Ferrel's, but he also finds in the tradewind zone that the wind direction at a mean height deviates from the direction of the trade, namely south-east, over the north-east trade-wind. At great heights the westerly winds prevail from the equator to the pole, without passing to calms in the horselatitudes. At the equator there exists an actual conical calmzone pointing upwards, in which only ascending air-currents prevail up to the highest altitudes.

Although, owing to the esteem which Sprung's treatise everywhere found, this theory of the general circulation of the atmosphere continued to spread, it did not arouse great inierest, because it did not take special account of the influence of these general currents on the formation and propagation of cyclones, which justly continued to attract the most general attention.

This influence of the general atmospheric circulation was first insisted upon by the celebrated physicist and mechanician, Werner Siemens, in I886. He considered the origin of the general circulation of the atmosphere from the great and fruitful principle of the conservation of energy.

Siemens introduced his far-seeing considerations with the remark that, even if Dove's theory of the general circulation of the atmosphere, which consisted of the ascending air-current at the equator, and the development therefrom of the equatorial and polar current with its conflicts for mastery in the temperate zones, were defective, yet this explanation was at all events more satisfactory than the "present almost exclusive reference of the motions of the air in higher latitudes to minima and maxima of pressure." He rightly asks that the seat of the forces-which accumulate, in a manner that is not at present evident, powerful energy in the cyclones and anticyclones which produce storms and whirlwinds-and the point of their attack may be indicated. Siemens makes no new assertion when he attributes all the energy which occurs in cyclones and anticyclones to the heat of the sun, but he discusses in a new and very noteworthy manner the way in which the sun's heat produces the storms of our latitudes.

Siemens explains the general circulation of the atmosphere according to the following principles :-(I) Without the heat of the sun the earth's atmosphere would be in a state of relative repose, i.e. it would everywhere rotate with the angular velocity of the earth's rotation; we should have no winds. (2) In reality, the earth and its atmosphere are unequally heated, most at the equator and least at the poles; consequently, air currents must arise from the equator towards the poles. (3) The energy which is accumulated by the rotation of the atmosphere about the earth's axis must, however, remain constant and unchanged; the theory of the conservation of energy requires this. If, therefore, a continual change of the geographical position of masses of air takes place through equatorial and polar air currents, it must take place so that the velocity of rotation of the whole atmosphere remains unchanged. This is only the case when the velocity of rotation of the whole atmosphere over lower latitudes lags behind that of the earth, but in higher latitudes outstrips it.

It is evident from this that anywhere in middle latitudes, both north and south, there must be a belt round the earth where neither a retardation nor an acceleration oscurs, i.e. where the air is in relative repose with regard to the earth. Siemens calculates the position of this belt to be at latitude $35^{\circ}$.

According to Siemens, therefore, we have the following system of air circulation :-

Between latitude $35^{\circ} \mathrm{N}$. and $35^{\circ} \mathrm{S}$, the general movement of the atmosphere is directed towards the west, i.e. east winds constantly prevail there in all latitudes and at all heights. In the vicinity of the equator, where north-east and south-east trades meet, an interference occurs at the surface of the earth, which produces the calm-zone, but it does not reach to any considerabie height. In the higher regions above the calm-zone, an east wind must likewise prevail.

In the higher latitudes, therefore, northward and westward of the $35^{\text {th }}$ parallels, the general movement of the atmosphere must be directed towards the eastward, and west winds must generally prevail in these latitudes.

Now, what do direct observations say to this system of the general circulation of the atmosphere?

There is no doubt that between the $35^{\text {th }}$ parallels an easterly air current prevails, viz. the trade-winds. It is also known that west winds prevail in the higher latitudes, and in the southern hemisphere they blow almost uninterruptedly. But Siemens's theory is not to be considered as proved by these general facts, although they are fully borne out in Ferrel's and Sprung's explanations; we must examine what is new in it more closely. Siemens's exposition requires an easterly air current at the equator, and even in the upper regions above the calm-zone. Does this exist? Until a short time ago, it was undoubtedly the general opinion of meteorologists that the calm-belt was a zone of actual calms up to the highest altitudes, and that only the slowly ascending current prevailed there; in the vicinity of the calm-zone, the trade-wind blowing below ought to rise, and with increasing height gradually assume a poleward direction, to appear soon as an upper south-west trade-wind. This theory, which had become rooted by custom and time, was upset by Siemens : between the $35^{\text {th }}$ parallels there are only easterly currents-the strongest and most purely easterly over the calmbelt, and decreasing continually towards latitude $35^{\circ}$; in the upper regions, on approaching latitude $35^{\circ}$, these currents come continually more from the south, and at the earth's surface more from the north. This was then a serious revolution in the theory of the general circulation of the atmosphere, which even the great authority of Siemens could not carry through without further experimental proofs. He had not reduced his investigations to a mathematical form, and so his theory, notwithstanding the great respect due to his name, would with difficulty have obtained greater success, if facts had not recently become known, which appeared to confirm it.

It is known that after the Krakatão eruption, in the year I 883 , the opinion was expressed that the frequent coloured phenomena of the sun in the tropics and the long evening glows were regarded as consequences of this eruption. The spread of these phenomena in the first ten days after the eruption was such that we were obliged to assume that the dust-haze thrown out had travelled round the earth in about twelve days from east to west ; for the explanation of the diffusion of these phenomena, a violent easterly wind was required in the upper regions of the atmosphere in the vicinity of the equator. For a long time it was this easterly wind which threw doubt upon the whole hypothesis of the unusual appearances which were referred to the Krakatao eruption. But Siemen's theory of the general circulation of the atmosphere was thereby confirmed. It appeared, however, as if here two hypotheses happened to mutually support each other, and it was a long time before on the one hand the Krakatão hypothesis, and on the other Siemens's theory, were regarded as established.

This theory found however further support-on one hand in the observations of the motion of high clouds by Abercromby, and on the other in the mathematical establishment of Siemens's statement by Oberbeck.

In 1885 , A bercromby, during a voyage from Aden to Australia, had observed that in the neighbourhood of the equator the cirrus moved from the east. He was much surprised at this, and wrote: "The discovery of an easterly current over the north-west monsuon is not only altogether new, but also quite anomalous." He thought this so important, that he undertook another voyage from Mauritius to Bombay, in order to clear up the matter. The result of his further observations is couched in the following terms : "I may point out another very important result of these observations-namely, that the highest air

$$
\text { NO. I I 73, VOL. 45] }
$$


current between the equator and the doldrums is always from some point near east." I

Here, then, was another actual confirmation of Siemens's theory. Two facts-the diffusion of the Krakatão dust, and Abercromby's observations--supported Siemens's theory of air circulation, yet doubts were not quite removed. Voices were loud against the Krakatão hypothesis and against Abercromby's observations, which allowed another explanation to appear possible. Meteorologists delayed mostly to accept Siemens's theory, because a theoretical, mathematical establishment of it was still lacking. But this was given, as before observed, by Oberbeck, a year or so ago. He arrived at formulæ by which Siemens's theory could be reproduced.

Now, in fact, nothing more was wanting. Siemens's system was confirmed on all sides, by facts and by mathematical treatment. The chief merit for this is certainly due to Oberbeck. Before I bring to your notice the system of the general circulation of the atmosphere, such as it is given by the present state of research, I must allude to one other point in Siemens's expositionnamely, the influence which the general circulation of the atmosphere should have on the origin of cyclones and anticyclones in our latitudes.

The origin of the maxima ought to be due to the fact that the air flowing from lower to higher latitudes is checked in consequence of the convergence of meridians, and so produces an increase of pressure. Thus we get the maxima, or anticyclones. If, then, in consequence of this increase of pressure below, air flows out laterally, and, in consequence of the interference, the confined current turns more to the eastward, it must carry the lower strata with it, and give rise to a rarefaction, causing a minimum or cyclone. But this is carried away as a whole by the general current, and thus the progression of cyclones is also explained.

Siemens holds very strongly to this explanation, principally because it contains a force which explains the energy which is accumulated in anticyclones and cyclones, and which refers finally to the heat of the sun, that maintains the general circulation. But I fear he has overshot the mark here. The meridians converge in the southern hemisphere the same as in the northern. Why, then, do almost constant west winds prevail there below, without interference of currents, while with us an almost uninterrupted system of driving cyclones and anticyclones exists? Does not this prove that in the formation of cyclones. and anticyclones another factor is at work, and might not this perhaps depend on the peculiar distribution of land and water in the northern hemisphere? Upon this point Siemens will have to modify his views.

From my analysis we can easily sketch the outline of the general circulation of the atmosphere which corresponds to the present state of the science.

In consequence of the unequal heating of the sun and of the rotation of the earth, air currents occur at all parts of the globe. These currents are easterly between $35^{\circ} \mathrm{N}$. and $35^{\circ} \mathrm{S}$. latitude, and westerly outside this zone.

In the former zone the easterly currents on the earth's surface (in the northern hemisphere) are more north-easterly and northerly the nearer we approach latitude $35^{\circ}$, while in the higher strata they constantly become more southerly as we approach latitude $35^{\circ}$. This explains the circulation between the equator and latitude $35^{\circ}$. An upper south-west trade-wind entirely fails in this region. ${ }^{2}$ At or near the equator a calm zone must be formed at the earth's surface, where the meridional components of the north-east and south-east trades ascend, but the height of the calm-zone cannot be considerable. Exactly over the calm-zone a pure east wind and the strongest of the whole zone will blow, and the higher the strata under consideration the stronger it will be.

In latitude $35^{\circ} \mathrm{N}$. and S., calms exist at the earth's surface. The air, which has an ascending motion in the equatorial calm, has here a descending movement. But above, the current directed polewards continues to exist. Outside this great region, to the north and south, west winds will prevail ; while above, the south-west (or the north-west) trade-wind blows, which in higher latitudes will become more and more westerly. At the earth's surface, air in south-westerly or north-westerly

I Mr. Abercromby afterwards modified this opinion (NATURE, vol. xxxix p. 437). - Translator.

2 This statement as to the failure of the upper south-west trade-wind between the equator and lat. $35^{\circ}$ was afterwards modified (see Das Wetter, 189o, p. 158).-Translator.

NO. I I 73, VOL. 45$]$ motion flows from the zone of high pressure at latitude $35^{\circ}$, which becomes more westerly with increasing latitude. At a mean altitude, however, air flows again from the poles towards latitude $35^{\circ}$ as a north. west wind.

This is the picture of the general circulation of the atmosphere according to the latest researches. There is undoubtedly much to be completed, and it presents many dark points which remain to be cleared up, but on the whole it possesses every guarantee of truth and reality, and will doubtless soon be generally accepted. The question of the effect upon cyclones and anticyclones of this general circulation of the atmosphere will certainly come to the front, but we shall have to wait for a considerable time for a satisfactory solution of the problem.

\section{RELATION OF VOLTAIC ELECTROMOTIVE FORCE TO MOLECULAR VELOCITY.}

I $\mathrm{N}$ a recent research published in vol. viii., p. 63, of the Proceedings of the Birmingham Philosophical Society, 1892, it is shown, by means of an extensive series of sixty-four tables of measurements of mean volta electromotive force, that the dilution of the liquid of a voltaic cell by means of water or alcohol, the liquefaction of either the positive or negative metal of the cell by means of mercury, the dilution of either of these amalgams by means of mercury, or the dilution of one solid metal by means of another in an alloy, is universally attended by an increase of mean electromotive force of the diluted and diluting substances, and consequently also of the actual electromotive force of the diluted one, provided that in all cases no chemical union or other chemical change occurs in the mixture. The manifest explanation of this extensive general result is that, by the act of solution or dilution, the molecules of the active substance are separated farther apart, and consequently acquire increased velocity of motion. In proportion, however, as chemical union occurs, the gain of electromotive force diminishes and is converted into a loss, and the loss is larger in proportion as the chemical union is stronger. The method enables chemical compounds in alloys, amalgams, and electrolytes to be distinguished from mere mechanical mixtures.

G. GORE.

\section{SCIENTIFIC SERIAISS.}

IN the Botanical Gazette for February and March, Miss Alice Carter has an interesting paper on evolution in methods of pollination. She points out that the larger proportion of Monocotyledons are either anemophilous or hydrophilous, and this is undoubtedly an earlier method of pollination than the entomophilous. Of the twenty-three natural orders which comprise more than 1000 species, only five are characterized by inconspicuous flowers. Of these, four, viz. the Cyperaceæ, Gramineæ, Urticaceæ, and Piperaceæ, are probably ancestral types, the fifth, Euphorbiaceæ, degenerate. It is probable that the period of the appearance of Dicotyledons was also that of the development of our great groups of insects. The first step towards the attraction of insects was probably the colouring of the stamens, as in Thalictrum and Plantago; then the development and colouring of the corolla, and the production of saccharine secretions. The most highly developed orders appear to be those in which the number of parts in a floral whorl is small, as the Violaceæ, Compositæ, Labiatæ, and Scrophulariaceæ.- $\mathrm{Mr}$. P. H. Rolfs has an article on the Seed-coats of Malvaceæ; and Mr. Chas. Robertson continues his researches on Flowers and insects.

In the Fournal of Botany for March and April, Mr. E. A. L. Batters describes and figures a new marine alga, Gonimophyllum Buffha mi, the type of a new genus. It belongs to the Delesseriacex, an order of Florideæ, and is epiphytic on Nitophyllum laceratum, being in fact nearly allied genetically to its host-plant. It was obtained from the coast near Deal.-Mr. R. J. Harvey Gibson describes the hitherto unknown antherids of Polysiphonia elongella, the mode of escape and conjugation of the zoogametes of Enteromorpha compressa, and the mode of development of the spores of British marine species of Chantransia.-Mr. E. G. Baker continues his Synopsis of the genera and species of Malveæ; and Mr. W. H. Clarke his First records of British 